\title{
Radiation tolerance of ceramics-Insights from atomistic simulation of damage accumulation in pyrochlores
}

\author{
Ram Devanathan, ${ }^{\mathrm{a},{ }^{*}}$ William J. Weber ${ }^{\mathrm{b}, \mathrm{c}}$ and Julian D. Gale ${ }^{\mathrm{d}}$ \\ ${ }^{a}$ Chemical \& Materials Sciences Division, Pacific Northwest National Laboratory, MS K2-01, \\ Richland, WA 99352, USA \\ ${ }^{\mathrm{b}}$ Department of Materials Science \& Engineering, University of Tennessee, Knoxville, TN \\ 37996, USA \\ ${ }^{\mathrm{c}}$ Materials Science \& Technology Division, Oak Ridge National laboratory, Oak Ridge, TN \\ 37831, USA \\ ${ }^{\mathrm{d}}$ Nanochemistry Research Institute, Department of Chemistry, Curtin University of Technology, \\ P.O. Box U1987, Perth, WA, 6845, Australia
}

*Corresponding author: E-mail: ram.devanathan@pnl.gov ～Phone: 1-509-371-6487

\begin{abstract}
We have used molecular dynamics simulations to investigate the effects of radiation damage accumulation in two pyrochlore-structured ceramics, namely $\mathrm{Gd}_{2} \mathrm{Ti}_{2} \mathrm{O}_{7}$ and $\mathrm{Gd}_{2} \mathrm{Zr}_{2} \mathrm{O}_{7}$. It is well known from experiment that the titanate is susceptible to radiation-induced amorphization, while the zirconate does not go amorphous under prolonged irradiation. Our simulations show that cation Frenkel pair accumulation eventually leads to amorphization of $\mathrm{Gd}_{2} \mathrm{Ti}_{2} \mathrm{O}_{7}$, and both anion disorder and cation disorder occur during damage accumulation. Amorphization in $\mathrm{Gd}_{2} \mathrm{Ti}_{2} \mathrm{O}_{7}$ is accompanied by a density decrease of about $12.7 \%$ and a decrease of about $50 \%$ in the elastic modulus. In $\mathrm{Gd}_{2} \mathrm{Zr}_{2} \mathrm{O}_{7}$, amorphization does not occur, because the residual damage introduced by radiation is not sufficiently energetic to destabilize the crystal structure and drive the material amorphous. Subtle differences in damage accumulation and annealing between the two pyrochlores lead to drastically different radiation response as the damage accumulates.
\end{abstract}




\section{Introduction}

Worldwide expansion of nuclear power has been proposed as a solution to the problems associated with rising global energy use, excessive dependence on energy production from combustion of fossil fuels and the resulting adverse environmental impact, such as the emission of green house gases and pollutants. ${ }^{1}$ With increased use of nuclear power, one has to deal with the concerns of nuclear proliferation and nuclear waste management. ${ }^{2,3}$ In this regard, the safe immobilization of toxic nuclear waste, actinides in spent nuclear fuel, and plutonium from dismantled nuclear weapons is a major challenge facing humanity today.

Due to the radiotoxicity of long-lived isotopes, e.g., ${ }^{239} \mathrm{Pu}$ has a half life of $\sim 24,200$ years, nuclear waste has to be isolated from the biosphere over time scales much longer than the span of recorded human history. This point is illustrated by Figure 1, which shows the half lives of selected actinides and fission products relevant to this article on a log scale. Burying nuclear waste in stable geologic formations is a widely recommended option. ${ }^{4}$ In this scheme, natural barriers to the migration of radionuclides are augmented by the use of multiple engineered barriers including compacted clay, drip shields and waste packages to keep water from contacting the waste, corrosion-resistant cladding, and a solid waste form that immobilizes actinides in a ceramic or glass matrix..$^{5}$

Currently, disposal of high-level waste by incorporation in borosilicate glass (vitrification) is preferred in the United States and several other countries, because vitrification is a well-understood technology, the processing steps are simple, the process is well established at the industrial scale, and glass can exist in different compositions and accept a wide variety of waste compositions. However, glass is metastable, likely to corrode in contact with water or 
humid air, and may be susceptible to radionuclide release due to microcracking. Moreover, the dissolution rate of glass may increase over time. Crystalline ceramics are promising alternatives, especially for the immobilization of $\mathrm{Pu}$ and minor actinides. Many ceramics proposed for waste form applications, such as zircon, become amorphous under prolonged exposure to radiation, ${ }^{6,7}$ which can lead to enhanced leaching of radionuclides and decline in mechanical properties. Ceramics that can survive in the extreme environment of radiation, elevated temperature and stress without losing their crystal structure hold the promise of acting as a reliable first line of defense by locking up actinides. In order to evaluate the performance of ceramic waste forms over a time scale of the order of 100,000 years we need a thorough understanding of the fundamental physics of radiation damage processes occurring at the atomic level.

Ceramics with the pyrochlore $\left(\mathrm{A}_{2} \mathrm{~B}_{2} \mathrm{O}_{7}\right)$ structure are leading candidates for the immobilization of $\mathrm{Pu}$ and minor actinides, and pyrochlores are components of several proposed ceramic waste forms. ${ }^{8}$ The crystal structure of pyrochlore is cubic (space group $F d 3 m$ ) with a large lattice parameter $(a)$ of about $1 \mathrm{~nm}$ as shown in Figure 2. One-eighth of the oxygen anions occupy the $8 b$ site, three-quarters occupy the $48 f$ site, and the remaining one-eighth of the anion sites $(8 a)$ are vacant. This structure is an ordered supercell of the well known cubic fluorite $(F m 3 m)$ structure. The pyrochlore structure is uniquely defined by the lattice parameter, $a$, and the $48 f$ oxygen positional parameter, $x$, which varies from 0.3125 in ideal pyrochlore to 0.375 in fluorite. The $48 f$ anion position is offset from that in ideal pyrochlore as cations of different radii are accommodated in the structure, and the $x$ parameter can be considered a measure of this offset. If oxygen is randomly distributed among anion sites with a site occupation probability of 0.875 and the cations are randomly exchanged, then the structure transforms from pyrochlore with the unit cell represented by the solid line in Figure 2, to disordered fluorite, with the unit 
cell represented by the dotted line. In this case, the value of $a$ of the disordered fluorite, $(\mathrm{A}, \mathrm{B})_{4} \mathrm{O}_{7}$, is half of that of the ordered pyrochlore, $\mathrm{A}_{2} \mathrm{~B}_{2} \mathrm{O}_{7}$.

In pyrochlore, the larger trivalent A cation is coordinated by six $48 f$ and two $8 b$ anions and the smaller tetravalent B cation is coordinated by six $48 f$ anions. The $48 f$ anion is coordinated by two cations of each type and the $8 b$ by four A cations. The anion vacancies are in an ordered arrangement in pyrochlore but randomly distributed in disordered fluorite, which is an important reason for the faster oxide ion diffusion in the latter. ${ }^{8}$ By varying the $\mathrm{A}$ and $\mathrm{B}$ cations in the formula unit, one can choose from hundreds of compositions, thereby tailoring the chemistry to incorporate a specific actinide (say, $\mathrm{Pu}$ ), neutron absorber (say, Gd) or fission product (say, Cs). Thus, the pyrochlore system offers a test-bed to examine the role of chemistry in the radiation tolerance of isostructural compounds.

Despite extensive experimental study, ${ }^{8-11}$ the mechanisms that govern radiation tolerance of ceramics are often difficult to unambiguously determine by experiment, because the atomiclevel processes are transient and occur over the nanometer length scale, multiple mechanisms may overlap, and there are limited facilities for the hazardous task of synthesis and characterization of radioactive samples. Experimental studies ${ }^{8,9}$ have shown that there is a systematic increase in the radiation tolerance of $\mathrm{Gd}_{2}\left(\mathrm{Zr}_{\mathrm{y}} \mathrm{Ti}_{1-\mathrm{y}}\right)_{2} \mathrm{O}_{7}$ pyrochlore with $y$ increasing from 0 to 1 . The radiation tolerance of pyrochlores have been linked ${ }^{8,11}$ to the ratio of ionic radius of $\mathrm{A}$ and $\mathrm{B}$ cations (1.74 for $\mathrm{Gd}_{2} \mathrm{Ti}_{2} \mathrm{O}_{7}$ and 1.46 for $\mathrm{Gd}_{2} \mathrm{Zr}_{2} \mathrm{O}_{7}$ ), and the $x$ position parameter of the $48 f$ oxygen site $\left(0.326\right.$ for $\mathrm{Gd}_{2} \mathrm{Ti}_{2} \mathrm{O}_{7}$ and 0.345 for $\left.\mathrm{Gd}_{2} \mathrm{Zr}_{2} \mathrm{O}_{7}\right)$.

Computer simulations are ideally suited to the length and time scales of damage accumulation processes, and one can simulate the effects of individual mechanisms in isolation. 
Molecular statics calculations have been previously used ${ }^{12,13}$ to examine cation antisite defect energies in compounds with the $\mathrm{A}_{2} \mathrm{~B}_{2} \mathrm{O}_{7}$ stoichiometry. The calculated antisite defect energy in pyrochlore was smallest for $\mathrm{Ce}$ as the B-site cation, intermediate for $\mathrm{Zr}$ and largest for Ti. These authors also performed experimental irradiation of $\mathrm{Er}_{2} \mathrm{Ti}_{2} \mathrm{O}_{7}$ and $\mathrm{Er}_{2} \mathrm{Zr}_{2} \mathrm{O}_{7}$ and concluded ${ }^{13}$ that ceramics with complex chemistry, complex structure, and an inherent propensity to accommodate lattice disorder should be able to resist amorphization and void swelling under irradiation. A subsequent study by the same group ${ }^{14}$ concluded that the energetic cost for the formation of cation anti-site defects and anion Frenkel pairs is a determining factor for the relative amorphization resistance of fluorite structural derivative compounds under irradiation.

While static calculations provide general trends in disorder energies that can be related to amorphization resistance, dynamical simulations are needed to fully examine the energetic processes associated with damage accumulation in ceramics. Molecular dynamics (MD) simulations of low energy displacement events ${ }^{15}$ in $\mathrm{Gd}_{2} \mathrm{Ti}_{2} \mathrm{O}_{7}$ and $\mathrm{Gd}_{2} \mathrm{Zr}_{2} \mathrm{O}_{7}$ have shown that there is a greater likelihood of producing clustered defects in the titanate. The accumulation of defect clusters can give rise to amorphization. Chartier et al. ${ }^{16-18}$ have performed a series of simulations of damage accumulation in pyrochlores. The authors have concluded ${ }^{17}$ that amorphization of pyrochlore is driven by Frenkel pair accumulation and that cation sublattice disorder drives the anion disorder. This appears to be at odds with the conclusions of an experimental irradiation study ${ }^{19}$ that cation disorder and anion disorder occur independently and that anion disorder occurs prior to cation disorder. A recent MD study of cation Frenkel pair accumulation in $\mathrm{Gd}_{2}\left(\mathrm{Zr}_{\mathrm{y}} \mathrm{Ti}_{1-\mathrm{y}}\right)_{2} \mathrm{O}_{7}$ has concluded ${ }^{18}$ that the formation of Ti-Ti dumbbells, which resist recombination with vacancies at low temperatures, plays a key role in the relative susceptibility to radiation-induced amorphization of the titanate compared to the zirconate. Such 
dumbbells were not observed in the zirconate pyrochlore. However, the structure of the Ti-Ti dumbbell and whether its formation was a cause or effect of amorphization is not clear from the above study.

In an effort to evaluate various defect mechanisms in pyrochlore and examine their effects on structure, swelling and mechanical properties, we have performed MD simulations of anion site exchange, cation site exchange, anion Frenkel pair accumulation and cation Frenkel pair accumulation in $\mathrm{Gd}_{2} \mathrm{Ti}_{2} \mathrm{O}_{7}$ and $\mathrm{Gd}_{2} \mathrm{Zr}_{2} \mathrm{O}_{7}$. Since previous simulations have shown that the occupation of the $8 a$ anion site is not favored in the titanate pyrochlore ${ }^{16}$ and the presence of structural vacancies can promote damage annealing in irradiated ceramics, ${ }^{20}$ we have analyzed the occupation of the $8 a$ site. In the present report, the details of the method are presented in Section 2, the results are discussed in Section 3 and the findings are summarized in Section 4.

\section{Details of the simulation}

We have performed classical MD simulations of radiation damage accumulation in $\mathrm{Gd}_{2} \mathrm{Ti}_{2} \mathrm{O}_{7}$ and $\mathrm{Gd}_{2} \mathrm{Zr}_{2} \mathrm{O}_{7}$ using the shell-model potential of Minervini et $\mathrm{al}^{12}$ that has been used in previous molecular statics calculations of defect energies in pyrochlore. ${ }^{12-14}$ This potential assigns formal charges $\left(\mathrm{Gd}^{3+}, \mathrm{Ti}^{4+}, \mathrm{Zr}^{4+}\right.$ and $\left.\mathrm{O}^{2-}\right)$ to the ions. In addition to the long-range Coulomb interaction, the potential has a short range interaction of the Buckingham form, given by:

$V_{i j}=A \exp \left(-r_{i j} / \rho\right)-C / r_{i j}{ }^{6}$,

where $A, \rho$ and $C$ are parameters fitted to known equilibrium properties of pyrochlores and $r_{i j}$ is the distance between ions $i$ and $j$. The polarizability of the ions is taken into account by treating 
the ion as a massive charged core connected by an isotropic harmonic spring to a massless charged shell. The sum of the core and shell charges equals the formal charge of the ion. The parameters of the potential can be found in the previous work of Minervini et al. ${ }^{12}$

Our choice of the potential of Minervini et $\mathrm{al}^{12}$ was dictated by its transferability to a wide range of pyrochlore compositions and the availability of an extensive database of defect energies from previous work. ${ }^{13-14}$ The potential was fitted by a spline function to the well-known Ziegler-Biersack-Littmark potential ${ }^{21}$ for $r_{i j}$ less than $0.1 \mathrm{~nm}$ to avoid unphysical attraction of ions at close separation due to the dispersion term $\left(-C / r_{i j}{ }^{6}\right)$ in the Buckingham potential. The long-range Coulomb sum was treated using the smooth particle mesh Ewald method. ${ }^{22}$

Classical MD simulations were performed using the DL_POLY computer code. ${ }^{23}$ The simulation cell contained 704 atoms ( $2 \times 2 \times 2$ unit cells) with periodic boundaries. The small size of the simulation cell was necessitated by the need to study hundreds of defect configurations. Simulations of radiation damage were performed without the use of the shell model in the above potential because of the instability of the shell model system under the non-equilibrium conditions created by radiation damage accumulation.

The simulation cell was initially equilibrated in the isothermal isobaric ensemble at 300 $\mathrm{K}$ and zero external pressure (constant NPT ensemble with Berendsen barostat and thermostat ${ }^{24}$ ) for 10 ps. Four different mechanisms of radiation damage were simulated, namely anion exchange between the $8 b$ and $48 f$ sites on the one hand and the $8 a$ site on the other; cation site exchange; anion Frenkel pair introduction and cation Frenkel pair introduction. Anion exchange was simulated by starting with the ordered pyrochlore crystal, randomly choosing a certain number of $8 b$ and $48 f$ anions (in the ratio 1:6) and placing them in randomly chosen vacant $8 a$ 
sites. Cation exchange was simulated in ordered pyrochlore by exchanging a certain number of randomly chosen A cations with randomly chosen B cations. Following the exchanges, the simulation cell was equilibrated for $10 \mathrm{ps}$ in the constant NPT ensemble as mentioned above followed by a $10 \mathrm{ps}$ production run.

Cation and anion Frenkel pairs were introduced as follows. A randomly chosen cation (or anion) was removed from its site and placed in an interstitial position $0.5 \mathrm{~nm}$ away from the original site along a random direction. The separation of $0.5 \mathrm{~nm}$ was chosen to prevent spontaneous vacancy-interstitial recombination. The condition that no other ions should be within $0.1 \mathrm{~nm}$ of the new location of the ion was imposed to avoid instability in the simulation. If any ion was found to be within $0.1 \mathrm{~nm}$ of the new location, the location was rejected and a new location was randomly chosen and the process repeated until the imposed condition was satisfied. It is possible for this process to choose a previously created interstitial and move it to a new site $0.5 \mathrm{~nm}$ away. After creation of the Frenkel pair, the simulation cell was relaxed in the constant NPT ensemble for 0.25 ps before the next Frenkel pair was introduced. The configurations were saved after each Frenkel pair introduction, and the simulation cells corresponding to different damage doses were equilibrated in the constant NPT ensemble for 10 ps as specified above. All the simulation runs used a variable time step algorithm with time step varying between 0.16 and 2.56 fs.

In addition to the ordered pyrochlore crystal as reference, an amorphous sample was generated by gradually heating the system to $8000 \mathrm{~K}$, maintaining it at $8000 \mathrm{~K}$ for $100 \mathrm{ps}$ and quenching the system from $8000 \mathrm{~K}$ to $300 \mathrm{~K}$ at the rate of $2 \times 10^{13} \mathrm{~K} / \mathrm{s}$. The configurations from MD simulations were visualized using $\mathrm{VMD}^{25}$ and $\mathrm{JMol}^{26}$ programs. The final configurations from MD runs were employed as input for optimization using the GULP code. ${ }^{27}$ In this step, the 
shell model, which could not be used in the dynamical simulations, was introduced and the energy of the system was minimized using the Newton-Raphson optimizer with BroydenFletcher-Goldfarb-Shanno updating of the Hessian matrix. ${ }^{28}$ The shell model was not used for $\mathrm{Zr}$, because the structure could not be optimized when defects were present. The mechanical properties of the system, such as bulk modulus, were also determined using the GULP code. ${ }^{27}$

\section{Results and discussion}

The changes in density and bulk modulus, energy increase in eV/atom and the occupancy of $8 a$ sites by oxygen with increasing levels of anion exchange are shown in Figure 3 for $\mathrm{Gd}_{2} \mathrm{Ti}_{2} \mathrm{O}_{7}$ and $\mathrm{Gd}_{2} \mathrm{Zr}_{2} \mathrm{O}_{7}$. The density and bulk modulus are shown as fractions of the values for a perfect crystal of ordered pyrochlore. For reference, the calculated density of the perfect

crystal is 6.66 and $6.81 \mathrm{~g} / \mathrm{cm}^{3}$ for $\mathrm{Gd}_{2} \mathrm{Ti}_{2} \mathrm{O}_{7}$ and $\mathrm{Gd}_{2} \mathrm{Zr}_{2} \mathrm{O}_{7}$, respectively. The corresponding bulk modulus values are 287 and $220 \mathrm{GPa}$. The density, bulk modulus and energy of the amorphous state are also shown in Figure 3 by the dashed, dashed and dotted, and solid lines, respectively. Amorphous $\mathrm{Gd}_{2} \mathrm{Ti}_{2} \mathrm{O}_{7}$ has a bulk modulus value that is $42.3 \%$ lower, density that is $8.7 \%$ lower and energy that is higher by $0.37 \mathrm{eV} /$ atom compared to the perfect crystal. While amorphous $\mathrm{Gd}_{2} \mathrm{Zr}_{2} \mathrm{O}_{7}$ has not been observed in irradiation experiments, one can create such a system in a simulation to use as a reference state. Our simulated amorphous $\mathrm{Gd}_{2} \mathrm{Zr}_{2} \mathrm{O}_{7}$ has a bulk modulus value that is $35 \%$ lower, density that is $7.2 \%$ lower and energy that is higher by $0.31 \mathrm{eV} /$ atom compared to the perfect crystal of $\mathrm{Gd}_{2} \mathrm{Zr}_{2} \mathrm{O}_{7}$ pyrochlore.

The anion exchange dose is expressed in terms of fraction of $8 a$ sites into which oxygen anions were introduced. The maximum fraction of $8 a$ sites exchanges was 0.875 , which 
corresponds to random occupation by oxygen of all available anion sites. The total number of $8 a$ sites in the simulation cell is 64 . During the equilibration of the simulation cell following the anion exchange, oxygen can jump from the $8 a$ site to a nearby $48 f$ vacancy. As a result of such jumps, the occupancy of the $8 a$ site never exceeds 0.1 in $\mathrm{Gd}_{2} \mathrm{Ti}_{2} \mathrm{O}_{7}$ even for the highest anion exchange fraction of 0.875 . In $\mathrm{Gd}_{2} \mathrm{Zr}_{2} \mathrm{O}_{7}$, the occupancy of $8 a$ sites goes as high as 0.3 after anion exchange, but the maximum energy increase is $0.06 \mathrm{eV} /$ atom compared to a maximum increase of $0.1 \mathrm{eV} /$ atom in $\mathrm{Gd}_{2} \mathrm{Ti}_{2} \mathrm{O}_{7}$. The zirconate appears to tolerate three times the amount of anion site disorder as the titanate with only about half the energy increase of the latter. This appears to be consistent with the conclusion of Chartier et al, ${ }^{16}$ based on simulation of the $\mathrm{La}_{2}\left(\mathrm{Zr}_{\mathrm{y}} \mathrm{Ti}_{1-\mathrm{y}}\right)_{2} \mathrm{O}_{7}$ system, that the occupation of the $8 a$ site is not favored in titanate pyrochlore.

In both $\mathrm{Gd}_{2} \mathrm{Ti}_{2} \mathrm{O}_{7}$ and $\mathrm{Gd}_{2} \mathrm{Zr}_{2} \mathrm{O}_{7}$, the introduction of anion site exchange has negligible effect on the bulk modulus and density of the system. We have examined the final configurations after equilibration at various levels of damage by using the Wigner-Seitz criterion. We scaled the lattice constants of perfectly ordered pyrochlore to the dimensions of the simulation cell and determined defects based on occupation of Wigner-Seitz cells centered on perfect lattice sites. The introduction of anion site exchanges did not lead to cation or anion Frenkel pairs or cation antisite defects. Thus anion site exchange by itself does not create lattice defects and is certainly not sufficiently energetic to drive amorphization in the two pyrochlores examined.

The effects of cation site exchange on the properties of $\mathrm{Gd}_{2} \mathrm{Ti}_{2} \mathrm{O}_{7}$ and $\mathrm{Gd}_{2} \mathrm{Zr}_{2} \mathrm{O}_{7}$ are shown in Figure 4. There are 128 A-type and 128 B-type cations in the system. The maximum number of exchanges attempted is 64 pairs of cations, which corresponds to random occupation of cation sites by A and B cations. The maximum change in the density of the titanate 
pyrochlore is about $2 \%$, while there is no appreciable change in the density of the zirconate pyrochlore. The maximum decrease in the bulk modulus is about $18 \%$ for $\operatorname{Gd}_{2} \operatorname{Ti}_{2} \mathrm{O}_{7}$ and about $5 \%$ for $\mathrm{Gd}_{2} \mathrm{Zr}_{2} \mathrm{O}_{7}$. These values are well below the values corresponding to the amorphous state, shown by straight lines. In both pyrochlores, the only defects identified by the Wigner-Seitz analysis are cation antisite defects. All the cation antisite defects introduced remain, but no other defects are produced apart from site exchanges on the anion sublattice (occupation of $8 a$ sites). The occupation of $8 a$ sites increases with increasing cation site exchange and reaches a maximum of 0.77 in $\mathrm{Gd}_{2} \mathrm{Ti}_{2} \mathrm{O}_{7}$ and 0.72 in $\mathrm{Gd}_{2} \mathrm{Zr}_{2} \mathrm{O}_{7}$. These values are comparable to the value of 0.875 for random oxygen distribution. The cation antisite disorder for a given fraction of cation site exchange is the same in the two pyrochlores and the occupation of the $8 \mathrm{a}$ sites is comparable. However, the maximum energy increase is $0.28 \mathrm{eV} /$ atom in $\mathrm{Gd}_{2} \mathrm{Ti}_{2} \mathrm{O}_{7}$ and only $0.06 \mathrm{eV} /$ atom in $\mathrm{Gd}_{2} \mathrm{Zr}_{2} \mathrm{O}_{7}$. While it is true that cation disorder leads to a larger energy increase in the titanate - consistent with previous molecular statics calculations ${ }^{12-14}$, completely random cation distribution with nearly completely random anion distribution on lattice sites is insufficient to amorphize either the titanate or the zirconate. In both pyrochlores, the energy increase and changes in the bulk modulus and density appear to saturate below the corresponding levels of the amorphous material with increasing levels of cation site exchange. Thus one cannot explain the difference in radiation tolerance of the two pyrochlores using arguments based strictly on cation and anion site disorder. Moreover, the high occupancy of $8 a$ oxygen sites in the titanate without amorphization suggests that radiation damage can be accommodated, at least in the early stages, in zirconate as well as titanate pyrochlores by site exchanges in cation and anion sublattices. 
Figure 5 shows the effects of anion Frenkel pair accumulation on the properties of $\mathrm{Gd}_{2} \mathrm{Ti}_{2} \mathrm{O}_{7}$ and $\mathrm{Gd}_{2} \mathrm{Zr}_{2} \mathrm{O}_{7}$. We simulated Frenkel pair accumulation up to 448 anion Frenkel pairs, which corresponds to the average anion being displaced once. The energy increase reaches a maximum of $0.13 \mathrm{eV} /$ atom for $\mathrm{Gd}_{2} \mathrm{Ti}_{2} \mathrm{O}_{7}$ and $0.1 \mathrm{eV} /$ atom for $\mathrm{Gd}_{2} \mathrm{Zr}_{2} \mathrm{O}_{7}$. The density change is less than $2 \%$ for the titanate and negligible for the zirconate. The maximum decrease in the bulk modulus is about $9 \%$ for the titanate and $5 \%$ for the zirconate. The occupancy of the $8 a$ sites is also minimal and comparable to the values produced by anion site exchange. The defects produced are mainly cation antisite defects in both pyrochlores. Very few of the introduced anion interstitials survive, because of the large number of vacancies $(8 a)$ built into the structure as previously demonstrated in a fluorite-structured ceramic. ${ }^{20}$ The interstitial can find a vacancy within the second neighbor distance, which facilitates vacancy-interstitial recombination and restoration of crystalline order. The presence of structural vacancies leads to effective anion interstitial annihilation and renders the anion Frenkel pair accumulation mechanism ineffective for amorphization of pyrochlore. The property changes appear to saturate at about 0.5 displacements per anion in $\mathrm{Gd}_{2} \mathrm{Ti}_{2} \mathrm{O}_{7}$ and 0.4 displacements per anion in $\mathrm{Gd}_{2} \mathrm{Zr}_{2} \mathrm{O}_{7}$. At the highest level of Frenkel pair introduction only about 14 out of 256 cations are on the wrong sites in $\mathrm{Gd}_{2} \mathrm{Ti}_{2} \mathrm{O}_{7}$ and $\mathrm{Gd}_{2} \mathrm{Zr}_{2} \mathrm{O}_{7}$. This is an interesting observation, because it shows that introducing displacements on the anion sublattice will lead to cation antisite defects. It contradicts the experimental interpretation ${ }^{19}$ that anion disorder precedes cation disorder. Cation disorder and anion disorder occur together in $\mathrm{Gd}_{2} \mathrm{Ti}_{2} \mathrm{O}_{7}$ and $\mathrm{Gd}_{2} \mathrm{Zr}_{2} \mathrm{O}_{7}$ as demonstrated by Figures 4 and 5. It appears that cation disorder is needed to maintain a high level of anion disorder in pyrochlore as previously shown by simulations of radiation effects in $\mathrm{La}_{2} \mathrm{Zr}_{2} \mathrm{O}_{7 \cdot}{ }^{17,29}$ This is also consistent 
with previous work that showed a reduction in anion defect energy due to the presence of an adjacent cation antisite pair. ${ }^{12}$

Figure 6 shows the property changes in $\mathrm{Gd}_{2} \mathrm{Ti}_{2} \mathrm{O}_{7}$ and $\mathrm{Gd}_{2} \mathrm{Zr}_{2} \mathrm{O}_{7}$ brought about by cation Frenkel pair introduction. Since there are 256 cations in the system, the maximum number of Frenkel pairs introduced was 256, which corresponds to each cation being displaced once on average. In $\mathrm{Gd}_{2} \mathrm{Ti}_{2} \mathrm{O}_{7}$, the energy of the disordered crystal increases above that of the amorphous state between 0.4 and 0.5 displacements per cation (dpc) and the maximum energy increase is $0.48 \mathrm{eV} /$ atom, which greatly exceeds the energy of melt-quenched amorphous $\mathrm{Gd}_{2} \mathrm{Ti}_{2} \mathrm{O}_{7}$. The maximum decrease in the bulk modulus is about $48 \%$ and the maximum decrease in density is about $12.7 \%$. The material is amorphized by Frenkel pair accumulation. The defects observed up to a damage dose of $0.375 \mathrm{dpc}$ consist mainly of cation antisite defects along with occupied $8 a$ oxygen sites. A few Ti Frenkel pairs are also present that provide the extra energy needed, above that provided by cation site exchange (Figure 4), to destabilize damaged pyrochlore relative to the amorphous state. The continued accumulation of Frenkel pairs also increases the system volume and degrades the elastic mechanical properties of the material.

In contrast, cation Frenkel pair introduction in $\mathrm{Gd}_{2} \mathrm{Zr}_{2} \mathrm{O}_{7}$ does not lead to amorphization. The property changes reach a steady state after about $0.1 \mathrm{dpc}$. The maximum density decrease is about $3 \%$ and the maximum decrease in the bulk modulus is about $20 \%$. The energy increases by about $0.25 \mathrm{eV} /$ atom, which is smaller than the relative energy of the amorphous state. The defects produced consist mainly of cation antisite defects and oxygens occupying the 8a sites. Nearly 60 pairs of cations out of 128 pairs are on "wrong" sites and the maximum occupancy of the 8 a sites by anions is about 0.72 . Thus, we have near complete randomization of cation and anion occupancy on lattice sites. A surprising observation is that some $\mathrm{Gd}$ and $\mathrm{Zr}$ Frenkel pairs 
(about 17 Frenkel pairs at the highest dose) are also present. This number is comparable to the number of $\mathrm{Ti}$ Frenkel pairs in $\mathrm{Gd}_{2} \mathrm{Ti}_{2} \mathrm{O}_{7}$ prior to amorphization. However, there are very few $\mathrm{Gd}$ interstitials in $\mathrm{Gd}_{2} \mathrm{Ti}_{2} \mathrm{O}_{7}$ prior to amorphization. The introduction of cation Frenkel pairs leads to cation antisite defects, anion site exchange and Frenkel pairs on both sublattices-defects that are observed in high energy displacement cascades in pyrochlore. ${ }^{30}$ Thus, cation Frenkel pair introduction can be taken to represent the radiation damage accumulation process in pyrochlore.

Our previous MD simulation study of $5 \mathrm{keV}$ and $30 \mathrm{keV} \mathrm{Gd}$ recoils in $\mathrm{Gd}_{2} \mathrm{Ti}_{2} \mathrm{O}_{7}$ and $\mathrm{Gd}_{2} \mathrm{Zr}_{2} \mathrm{O}_{7}$ using the same potential ${ }^{30}$ has shown that the number of cations displaced, cation interstitials and anti sites produced, and anions displaced is comparable for these two pyrochlores. In $\mathrm{Gd}_{2} \mathrm{Zr}_{2} \mathrm{O}_{7}$, there are more anion replacements and greater ionic mixing, which is proportional to the mean-square displacement of ions in displacement cascades produced by energetic recoils. As a result, fewer anion interstitials survive and there is a greater occupancy of 8a anion sites in $\mathrm{Gd}_{2} \mathrm{Zr}_{2} \mathrm{O}_{7}$ compared to $\mathrm{Gd}_{2} \mathrm{Ti}_{2} \mathrm{O}_{7}$. This is consistent with the well known faster ionic conductivity in $\mathrm{Gd}_{2} \mathrm{Zr}_{2} \mathrm{O}_{7}$. Anion diffusion is orders of magnitude faster in $\mathrm{Gd}_{2} \mathrm{Zr}_{2} \mathrm{O}_{7}$ than in $\mathrm{Gd}_{2} \mathrm{Ti}_{2} \mathrm{O}_{7}{ }^{31}$

The present results when combined with our previous simulations of recoil damage in pyrochlore $^{30}$ show that the fundamental differences that lead to the differing radiation tolerances of $\mathrm{Gd}_{2} \mathrm{Ti}_{2} \mathrm{O}_{7}$ and $\mathrm{Gd}_{2} \mathrm{Zr}_{2} \mathrm{O}_{7}$ pyrochlores are subtle. In both pyrochlores, radiation damage, as represented by cation Frenkel pair accumulation, is accommodated initially by cation exchange and occupation of $8 a$ sites by anions as A-site cation vacancies recombine with nearby B-type cation interstitials and B-site vacancies with A-type interstitials. These processes lead to a larger energy increase in the titanate, but are not sufficient to amorphize either the titanate or the 
zirconate. The change in density and bulk modulus are minimal at this stage especially compared to the changes brought about by amorphization.

As damage proceeds, cation interstitials may encounter higher energy barriers to recombination with cation vacancies, because the energy landscape for ionic migration has been unfavorably altered by cation antisite defects and anion site exchange. A recent damage accumulation study of pyrochlore using a different potential has attributed amorphization of $\mathrm{Gd}_{2} \mathrm{Ti}_{2} \mathrm{O}_{7}$ to the formation of Ti-Ti dumbbells. ${ }^{18}$ In any case, the cation Frenkel pairs that resist recombination provide the additional energy increase needed to drive the titanate pyrochlore amorphous. At this point, the material undergoes an increase in swelling and the bulk modulus becomes half of that of the crystal. In the zirconate, the energy increase saturates below the energy of the amorphous state. Due to the much lower energy of cation anti-site defects in $\mathrm{Gd}_{2} \mathrm{Zr}_{2} \mathrm{O}_{7}$ relative to that in $\mathrm{Gd}_{2} \mathrm{Ti}_{2} \mathrm{O}_{7}{ }^{12}$ cation Frenkel pair recombination may not be significantly impeded in the zirconate by the presence of cation antisite defects. As a result, the energy and volume increases are small and the crystal is not destabilized.

The processes described about can be visualized from the sequence of images shown in Figure 7 for $\mathrm{Gd}_{2} \mathrm{Ti}_{2} \mathrm{O}_{7}$ and Figure 8 for $\mathrm{Gd}_{2} \mathrm{Zr}_{2} \mathrm{O}_{7}$. Depth cuing is used to show atoms at a greater depth in a lighter shade. Figure 7 shows the progression of damage in $\mathrm{Gd}_{2} \mathrm{Ti}_{2} \mathrm{O}_{7}$ for cation Frenkel pair accumulation from $0.03 \mathrm{dpc}$ to $0.625 \mathrm{dpc}$. Cation disorder is evident in the early stages and the system is topologically ordered up to $0.375 \mathrm{dpc}$. At $0.5 \mathrm{dpc}$, a mix of topologically ordered cation arrangement and topologically disordered regions can be seen in Figure 7(e), and there is considerable site exchange in the ordered regions. By $0.625 \mathrm{dpc}$, the material is clearly amorphous. We did not observe the Ti-Ti dumbbells reported by Chartier et al. ${ }^{18}$ In fact, the minimum Ti-Ti separation observed in the amorphous material was $2.8 \AA$. 
Given the strong Coulomb repulsion between cations, it is unlikely that a Ti-Ti dumbbell will form. The reported dumbbells are likely to be distorted Ti-O-Ti bond arrangements. It is not clear if these distorted Ti-O-Ti bonds cause the amorphization or if they are the result of the collapse of the crystal structure triggered by the combined effects of cation disorder, anion disorder and Frenkel pairs on both sublattices. It can certainly be argued that local bond distortions may form the nuclei of amorphous domains that grow and percolate with increasing damage. This is supported by the coexistence of disordered and ordered domains in $\mathrm{Gd}_{2} \mathrm{Ti}_{2} \mathrm{O}_{7}$ at $0.5 \mathrm{dpc}$ at the threshold of amorphization.

In contrast to the case of $\mathrm{Gd}_{2} \mathrm{Ti}_{2} \mathrm{O}_{7}$, Figure 8 shows that $\mathrm{Gd}_{2} \mathrm{Zr}_{2} \mathrm{O}_{7}$ remains ordered even at $1 \mathrm{dpc}$. The sequence of configurations following Frenkel pair accumulation, shows considerable cation site exchange, but topological order is maintained at all doses examined. Some regions of disorder are visible at $1 \mathrm{dpc}$, but they are isolated. Since $\mathrm{Gd}_{2} \mathrm{Zr}_{2} \mathrm{O}_{7}$ is a fast ion conductor, ${ }^{31}$ effective defect annealing predominantly by anion vacancy migration may prevent the percolation of disordered regions. Thus $\mathrm{Gd}_{2} \mathrm{Ti}_{2} \mathrm{O}_{7}$ and $\mathrm{Gd}_{2} \mathrm{Zr}_{2} \mathrm{O}_{7}$ appear to differ slightly in energetics of defect accumulation, at least in the early stages, and substantially in migration barriers for ions. ${ }^{31}$ Under prolonged irradiation, the cumulative effects of these differences in defect formation and migration energies shift the competition between damage accumulation and annealing towards amorphization, swelling and loss of mechanical properties in the case of the former and radiation tolerance in the case of the latter.

Previous work ${ }^{8,11}$ has related the radiation tolerance of pyrochlores to the cation radius ratio (1.74 for $\mathrm{Gd}_{2} \mathrm{Ti}_{2} \mathrm{O}_{7}$ and 1.46 for $\mathrm{Gd}_{2} \mathrm{Zr}_{2} \mathrm{O}_{7}$ ), and the $x$ position parameter of the $48 f$ oxygen site ( 0.326 for $\mathrm{Gd}_{2} \mathrm{Ti}_{2} \mathrm{O}_{7}$ and 0.345 for $\mathrm{Gd}_{2} \mathrm{Zr}_{2} \mathrm{O}_{7}$ ). A recent density functional theory-based study ${ }^{32}$ has shown that the disordering energy, i.e. energy difference between the disordered 
fluorite and ordered pyrochlore structures, increases with increasing deviation of the ionic radius ratio from unity and increasing deviation of the $x$ parameter from 0.375 (value for disordered fluorite). However, the relationship between disordering energy and radius ratio is not linear for titanate pyrochlores. ${ }^{32}$ Since cation and anion site exchange is not sufficient to drive pyrochlore amorphous, the above criteria can serve mainly as general guidelines to radiation tolerance. The present results when viewed in light or previous experimental and simulation results show that the ideal radiation-tolerant ceramic must have mechanisms to accommodate disorder with minimal increase in energy and volume, structural vacancies to annihilate interstitials and prevent their accumulation, and fast anion transport to anneal damage and prevent percolation of damaged regions. Large migration barriers for cation transport are also desirable if actinides are to be immobilized as cations in the ceramic.

\section{Conclusions}

We have used atomistic computer simulations to evaluate the efficacy of four damage accumulation mechanisms, namely anion site exchange, cation site exchange, anion Frenkel pair accumulation and cation Frenkel pair accumulation, in bringing about amorphization of pyrochlores. In $\mathrm{Gd}_{2} \mathrm{Ti}_{2} \mathrm{O}_{7}$, the first three mechanisms do not cause amorphization, while the fourth leads to amorphization with a decrease of $12.7 \%$ in the density and nearly $50 \%$ in the bulk modulus. In $\mathrm{Gd}_{2} \mathrm{Zr}_{2} \mathrm{O}_{7}$, none of the four mechanisms leads to amorphization. The energy increase brought about by cation Frenkel pair accumulation falls short of the stored energy of the amorphous state. The combination of less energetic defect accumulation processes and more effective dynamic annealing make $\mathrm{Gd}_{2} \mathrm{Zr}_{2} \mathrm{O}_{7}$ much more radiation tolerant than $\mathrm{Gd}_{2} \mathrm{Ti}_{2} \mathrm{O}_{7}$. 


\section{Acknowledgements}

This research was supported by the Division of Materials Science and Engineering, Office of

Basic Energy Sciences, U. S. Department of Energy (DOE) under Contract DE-AC05-

76RL01830. It was performed in part using the Molecular Science Computing Facility in the

Environmental Molecular Sciences Laboratory, a national scientific user facility sponsored by

the U.S. DOE, Office of Biological and Environmental Research and located at Pacific

Northwest National Laboratory (PNNL). JDG would like to thank the Australian Research

Council for a professorial fellowship.

\section{References}

1. W. C. Sailor, D. Bodansky, C. Braun, S. Fetter and R. van der Zwaan, Science, 2000, 288(5469), 1177-1178.

2. R. C. Ewing, MRS Bulletin, 2008, 33, 338-340.

3. S. S. Hecker, MRS Bulletin, 2008, 33, 340-342.

4. I. J. Winograd and E. H. Roseboom Jr., Science, 2008, 320(5882), 1426-1427.

5. $\quad$ R. C. Ewing, Proc. Natl. Acad. Sci., 1999, 96, 3432-3439.

6. I. Farnan, H. Cho and W. J. Weber, Nature, 2006, 445, 190-193.

7. R. Devanathan and W. J. Weber, JOM, 2007, 59, 32-35.

8. $\quad$ R. C. Ewing, W. J. Weber and J. Lian, J. Appl. Phys., 2004, 95, 5959.

9. S. X. Wang, B. D. Begg, L. M. Wang, R. C. Ewing, W. J. Weber and K. V. G. Kutty, J. Mater. Res., 1999, 14, 4470-4473.

10. S. X. Wang, L. M. Wang, R. C. Ewing and K. V. G. Kutty, Nucl. Instrum. Meth. B, 2000, 169, 135-140.

11. J. Lian, J. Chen, L. Wang, R. C. Ewing, J. M. Farmer, L. A. Boatner and K. B. Helean, Phys. Rev. B, 2003, 68, 134107.

12. L. Minervini, R. W. Grimes and K. E. Sickafus, J. Am. Ceram. Soc., 2000, 83, 1873-1878.

13. K. E. Sickafus, L. Minervini, R. W. Grimes, J. A. Valdez, M. Ishimaru, F. Li, K. J. McClellan and T. Hartmann, Science, 2000, 289 (5480), 748-751.

14. K. E. Sickafus, R. W. Grimes, J. A. Valdez, A. Cleave, M. Tang, M. Ishimaru, S. M. Corish, C. R. Stanek and B. P. Uberuaga, Nat. Mater., 2007, 6, 217-223.

15. R. Devanathan and W. J. Weber, J. Appl. Phys., 2005, 98, 086110.

16. A. Chartier, C. Meis, W. J. Weber, and L. R. Corrales, Phys. Rev. B, 2002, 65, 134116.

17. A. Chartier, C. Meis, J.-P. Crocombette, W. J. Weber, and L. R. Corrales, Phys. Rev. Lett., 2005, 94, 025505.

18. A. Chartier, G. Catillon and J.-P. Crocombette, Phys. Rev. Lett., 2009, 102, 155503. 
19. J. Lian, L. Wang, J. Chen, R. C. Ewing, J. M. Farmer and L. A. Boatner, Acta Materialia, 2003, 51, 1493-1502.

20. R. Devanathan and W. J. Weber, J. Mater. Res., 2008, 23, 593-597.

21. J. F. Ziegler, J. P. Biersack, and U. Littmark, The Stopping and Range of Ions in Matter Pergamon, New York, 1985.

22. U. Essmann, L. Perera, M. L. Berkowitz, T. Darden, H. Lee and L. G. Pedersen, J. Chem. Phys., 1995, 103, 8577-8593.

23. I. T. Todorov, W. Smith, K. Trachenko and M. T. Dove, J. Mater. Chem, 2006, 16, 19111918.

24. H. J. C. Berendsen, J. P. M. Postma, W. F. van Gunsteren, A. DiNola and J. R. Haak. J. Chem. Phys., 1984, 81(8), 3684-3690.

25. W. Humphrey, A. Dalke and K. Schulten, J. Mol. Graphics, 1996, 14(1), 33-38.

26. JMol: an open-source Java viewer for chemical structures in 3D. http://www.jmol.org/

27. J. D. Gale and A. L. Rohl, Mol. Simul., 2003, 29, 291-341.

28. D. F. Shanno, Math. Comput., 1970, 24, 647-656.

29. J.-P. Crocombette and A. Chartier, Nucl. Instrum. and Meth. B, 2007, 255, 158-165.

30. R. Devanathan and W. J. Weber, Nucl. Instrum. and Methods (submitted).

31. H. L. Tuller, Solid State Ionics, 1992, 52, 135-146.

32. C. Jiang, C. R. Stanek, K. E. Sickafus and B. P. Uberuaga, Phys. Rev. B, 2009, 79, 104203. 


\section{Figure Captions.}

Fig. 1. Half lives of selected actinides and fission products.

Fig. 2. The unit cell of the pyrochlore $\left(\mathrm{A}_{2} \mathrm{~B}_{2} \mathrm{O}_{7}\right)$ structure with the unit cell of the disordered fluorite $\left(\mathrm{AO}_{1.75}\right)$ shown by dotted lines. $\mathrm{A}$ and $\mathrm{B}$ cations are shown by grey and green spheres, while the red, blue and yellow spheres represent $48 f, 8 b$ and $8 a$ oxygen sites, respectively. The $8 a$ anion sites are vacant in pyrochlore.

Fig. 3. Changes in the energy increase per atom, occupancy of 8a anion sites, ratio of density to that of the perfect crystal, and ratio of bulk modulus to that of the perfect crystal for a) $\mathrm{Gd}_{2} \mathrm{Ti}_{2} \mathrm{O}_{7}$ and b) $\mathrm{Gd}_{2} \mathrm{Zr}_{2} \mathrm{O}_{7}$ as a function of anion site exchange fraction. The values of density, bulk modulus and energy of the amorphous state are represented by dashed, dotted and dashed and solid lines, respectively.

Fig. 4. Changes in the energy increase per atom, occupancy of 8a anion sites, ratio of density to that of the perfect crystal, and ratio of bulk modulus to that of the perfect crystal for a) $\mathrm{Gd}_{2} \mathrm{Ti}_{2} \mathrm{O}_{7}$ and b) $\mathrm{Gd}_{2} \mathrm{Zr}_{2} \mathrm{O}_{7}$ as a function of cation site exchange fraction. The values of density, bulk modulus and energy of the amorphous state are represented by dashed, dotted and dashed and solid lines, respectively.

Fig. 5. Changes in the energy increase per atom, occupancy of 8a anion sites, ratio of density to that of the perfect crystal, and ratio of bulk modulus to that of the perfect crystal for a) $\mathrm{Gd}_{2} \mathrm{Ti}_{2} \mathrm{O}_{7}$ and b) $\mathrm{Gd}_{2} \mathrm{Zr}_{2} \mathrm{O}_{7}$ as a function of displacements per anion. The values of density, bulk modulus and energy of the amorphous state are represented by dashed, dotted and dashed and solid lines, respectively. 
Fig. 6. Changes in the energy increase per atom, occupancy of 8a anion sites, ratio of density to that of the perfect crystal, and ratio of bulk modulus to that of the perfect crystal for a) $\mathrm{Gd}_{2} \mathrm{Ti}_{2} \mathrm{O}_{7}$ and b) $\mathrm{Gd}_{2} \mathrm{Zr}_{2} \mathrm{O}_{7}$ as a function of displacements per cation. The values of density, bulk modulus and energy of the amorphous state are represented by dashed, dotted and dashed and solid lines, respectively.

Fig. 7. Projection of atom positions in $\mathrm{Gd}_{2} \mathrm{Ti}_{2} \mathrm{O}_{7}$ following a) 0.03 ; b) 0.125 ; c) 0.25 ; d) 0.375 ; e) 0.5 and f) 0.625 displacements per cation. Gd, Ti and $\mathrm{O}$ are represented by green, grey and red spheres, respectively.

Fig. 8. Projection of atom positions in $\mathrm{Gd}_{2} \mathrm{Zr}_{2} \mathrm{O}_{7}$ following a) 0.25 ; b) 0.5 ; c) 0.75 and d) 1.0 displacements per cation. Gd, $\mathrm{Zr}$ and $\mathrm{O}$ are represented by green, grey and red spheres, respectively. 


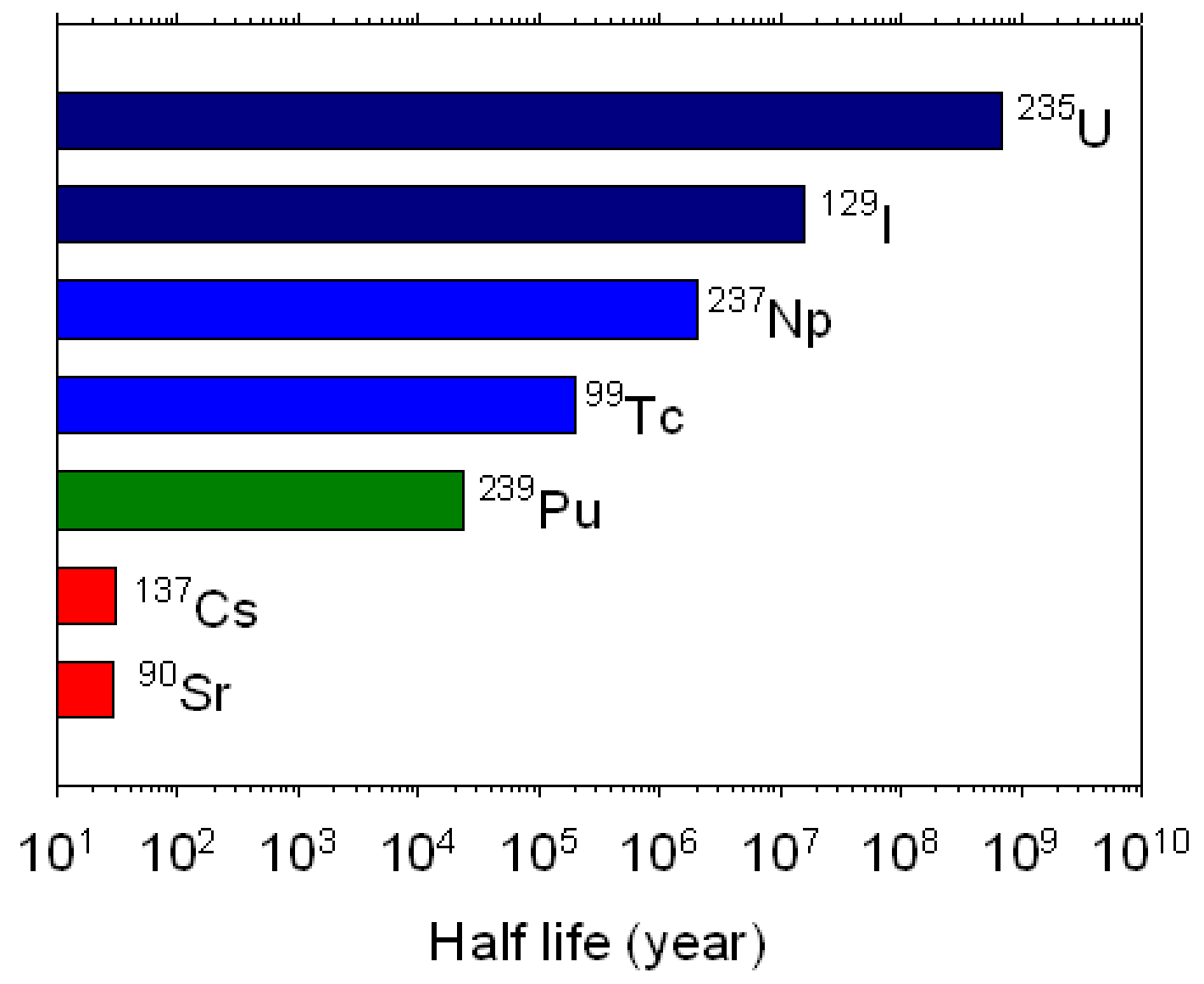

Fig. 1. Half lives of selected actinides and fission products. 


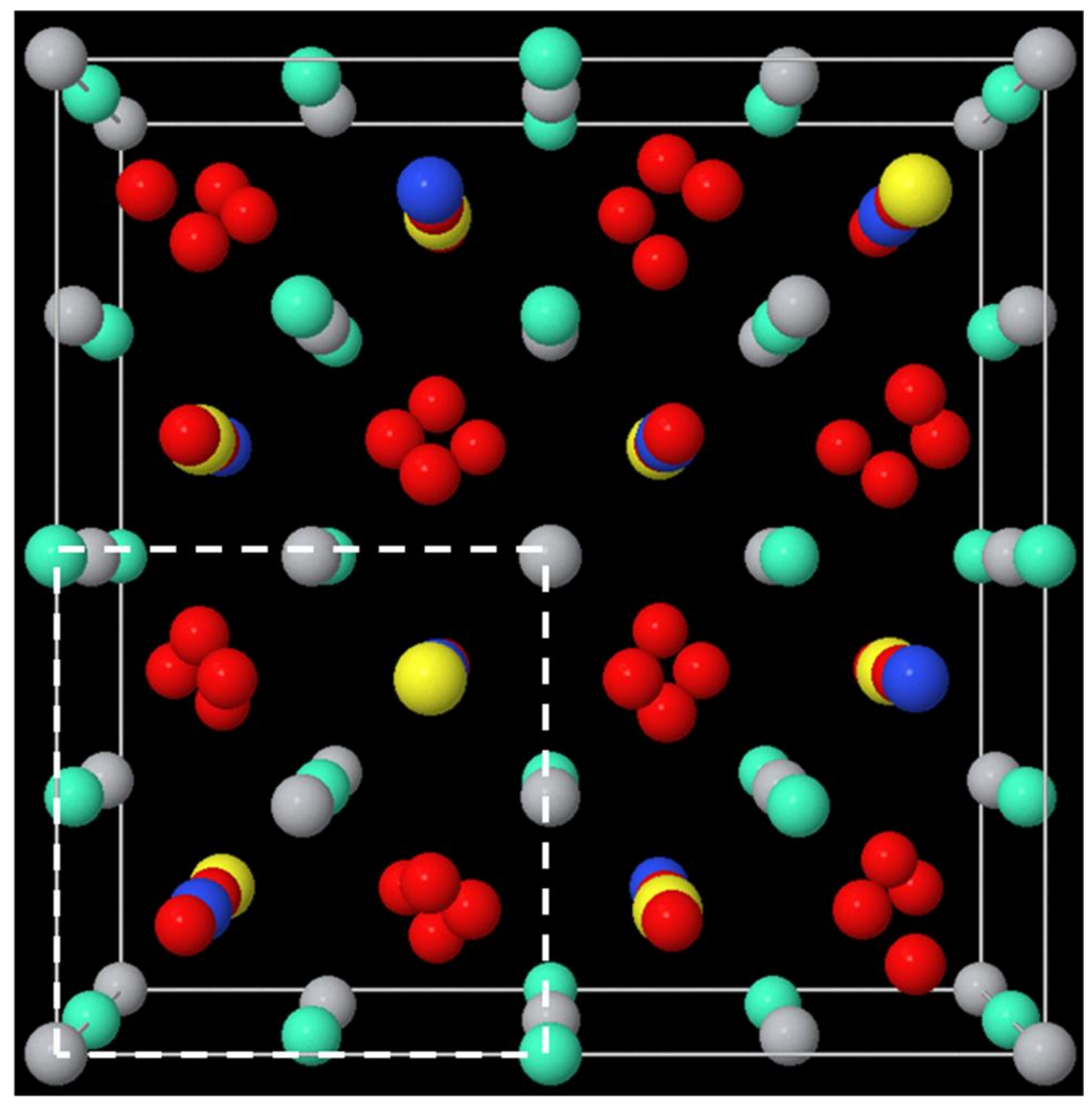

Fig. 2. The unit cell of the pyrochlore $\left(\mathrm{A}_{2} \mathrm{~B}_{2} \mathrm{O}_{7}\right)$ structure with the unit cell of the disordered

fluorite $\left(\mathrm{AO}_{1.75}\right)$ shown by dotted lines. $\mathrm{A}$ and $\mathrm{B}$ cations are shown by grey and green spheres, while the red, blue and yellow spheres represent $48 f, 8 b$ and $8 a$ oxygen sites, respectively. The $8 a$ anion sites are vacant in pyrochlore. 


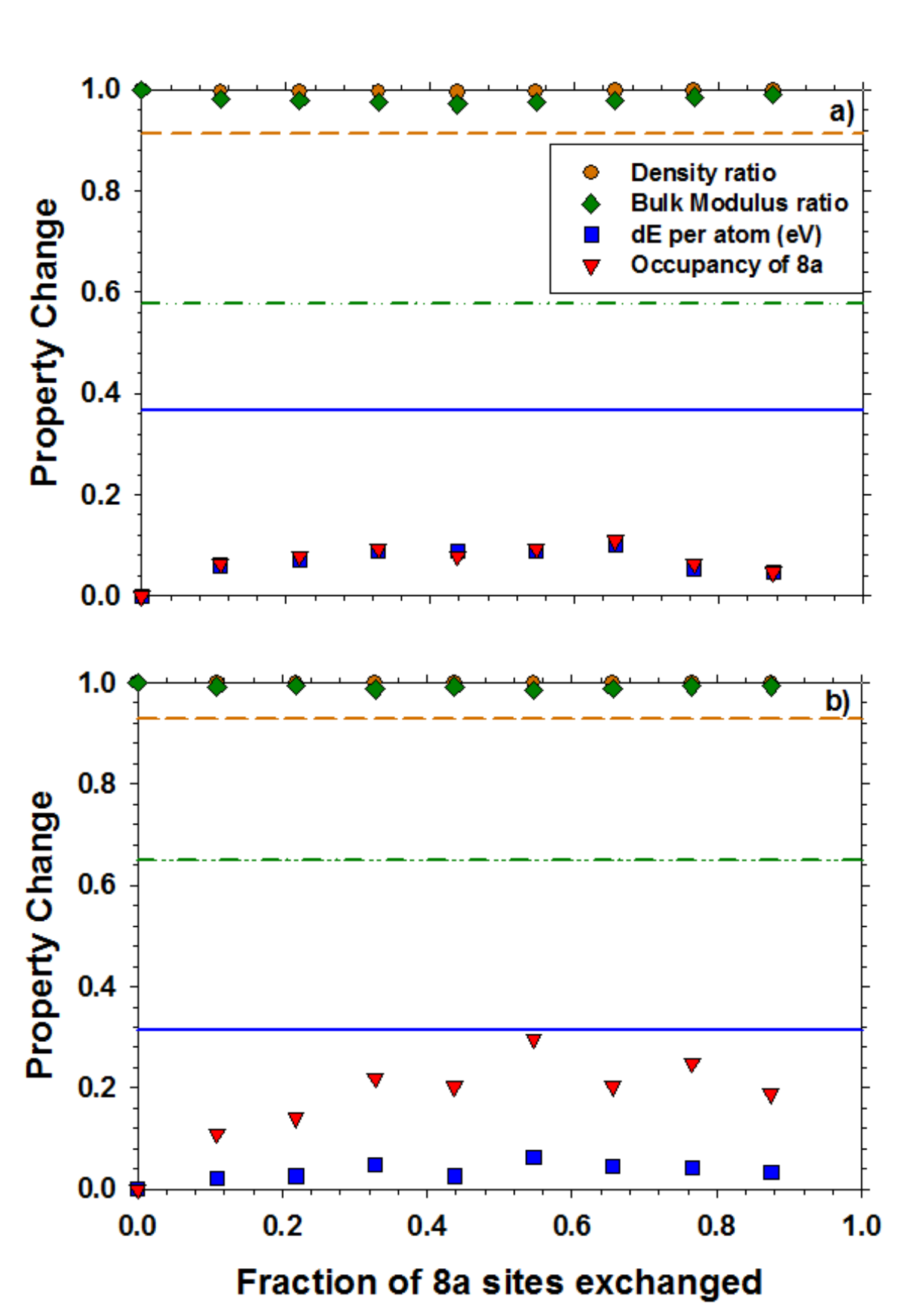

Fig. 3. Changes in the energy increase per atom, occupancy of $8 \mathrm{a}$ anion sites, ratio of density to that of the perfect crystal, and ratio of bulk modulus to that of the perfect crystal for a) $\mathrm{Gd}_{2} \mathrm{Ti}_{2} \mathrm{O}_{7}$ and b) $\mathrm{Gd}_{2} \mathrm{Zr}_{2} \mathrm{O}_{7}$ as a function of anion site exchange fraction. The values of density, bulk modulus and energy of the amorphous state are represented by dashed, dotted and dashed and solid lines, respectively. 


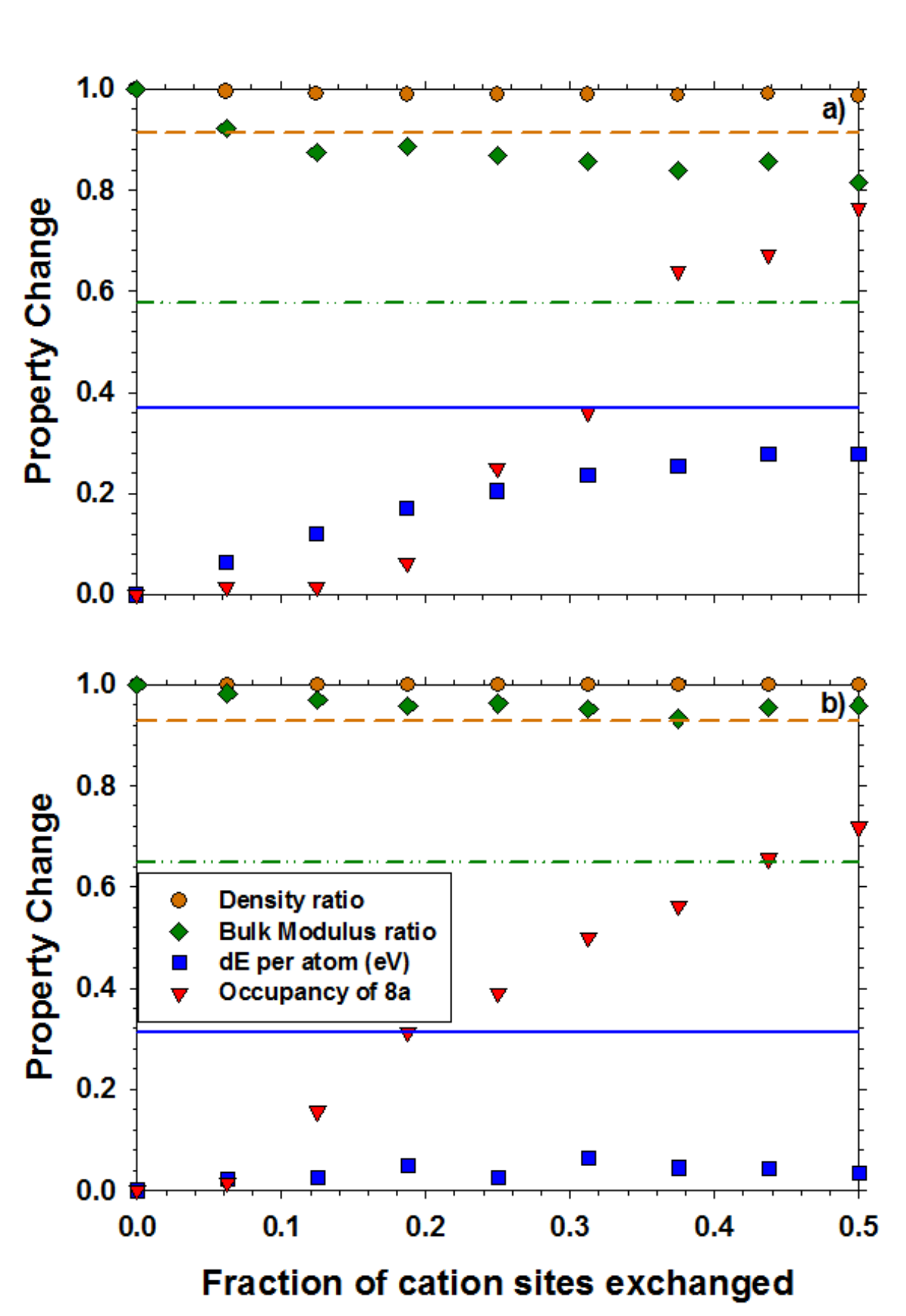

Fig. 4. Changes in the energy increase per atom, occupancy of 8a anion sites, ratio of density to that of the perfect crystal, and ratio of bulk modulus to that of the perfect crystal for a) $\mathrm{Gd}_{2} \mathrm{Ti}_{2} \mathrm{O}_{7}$ and b) $\mathrm{Gd}_{2} \mathrm{Zr}_{2} \mathrm{O}_{7}$ as a function of cation site exchange fraction. The values of density, bulk modulus and energy of the amorphous state are represented by dashed, dotted and dashed and solid lines, respectively. 


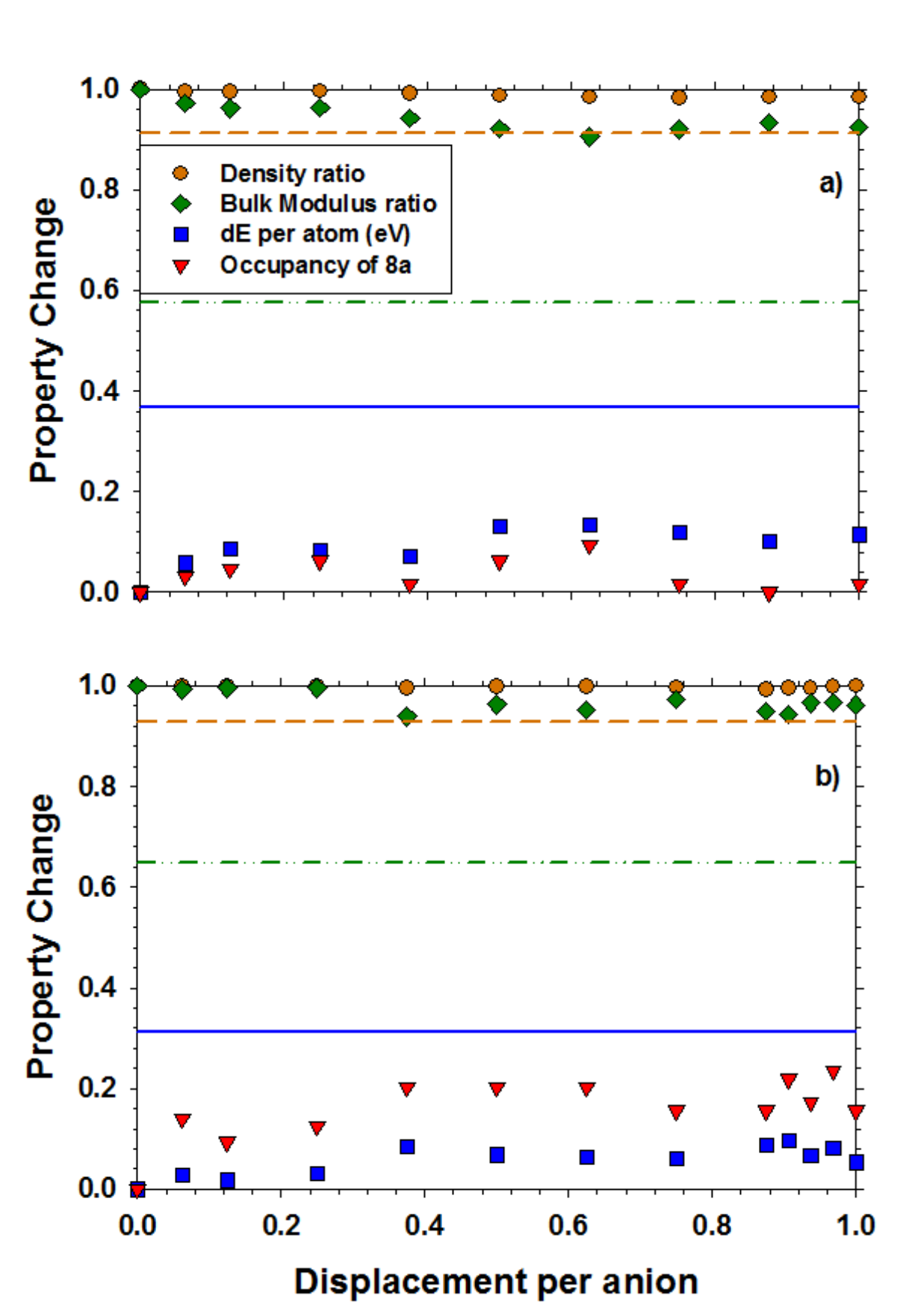

Fig. 5. Changes in the energy increase per atom, occupancy of $8 \mathrm{a}$ anion sites, ratio of density to that of the perfect crystal, and ratio of bulk modulus to that of the perfect crystal for a) $\mathrm{Gd}_{2} \mathrm{Ti}_{2} \mathrm{O}_{7}$ and b) $\mathrm{Gd}_{2} \mathrm{Zr}_{2} \mathrm{O}_{7}$ as a function of displacements per anion . The values of density, bulk modulus and energy of the amorphous state are represented by dashed, dotted and dashed and solid lines, respectively. 


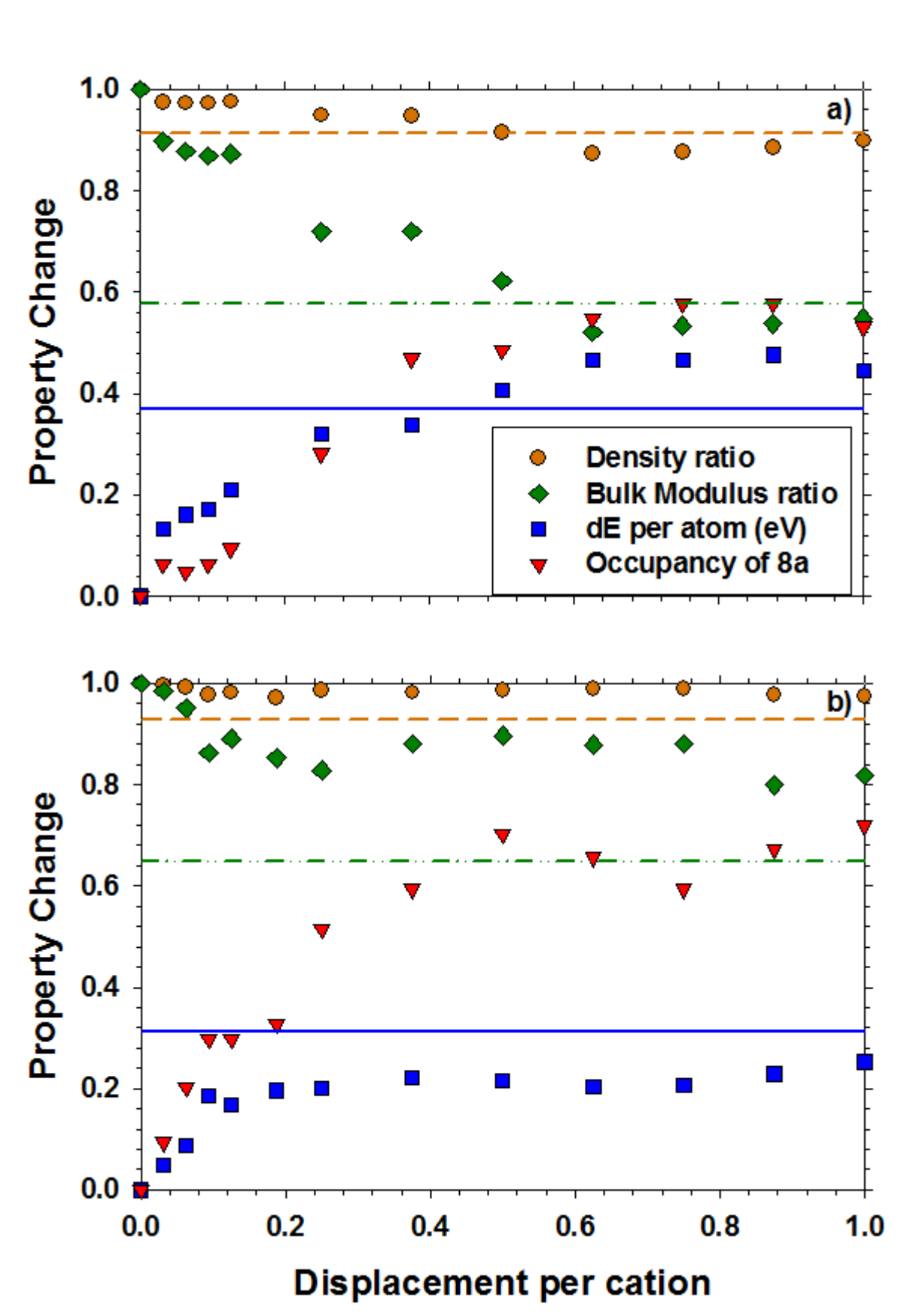

Fig. 6. Changes in the energy increase per atom, occupancy of $8 \mathrm{a}$ anion sites, ratio of density to that of the perfect crystal, and ratio of bulk modulus to that of the perfect crystal for a) $\mathrm{Gd}_{2} \mathrm{Ti}_{2} \mathrm{O}_{7}$ and b) $\mathrm{Gd}_{2} \mathrm{Zr}_{2} \mathrm{O}_{7}$ as a function of displacements per cation. The values of density, bulk modulus and energy of the amorphous state are represented by dashed, dotted and dashed and solid lines, respectively. 

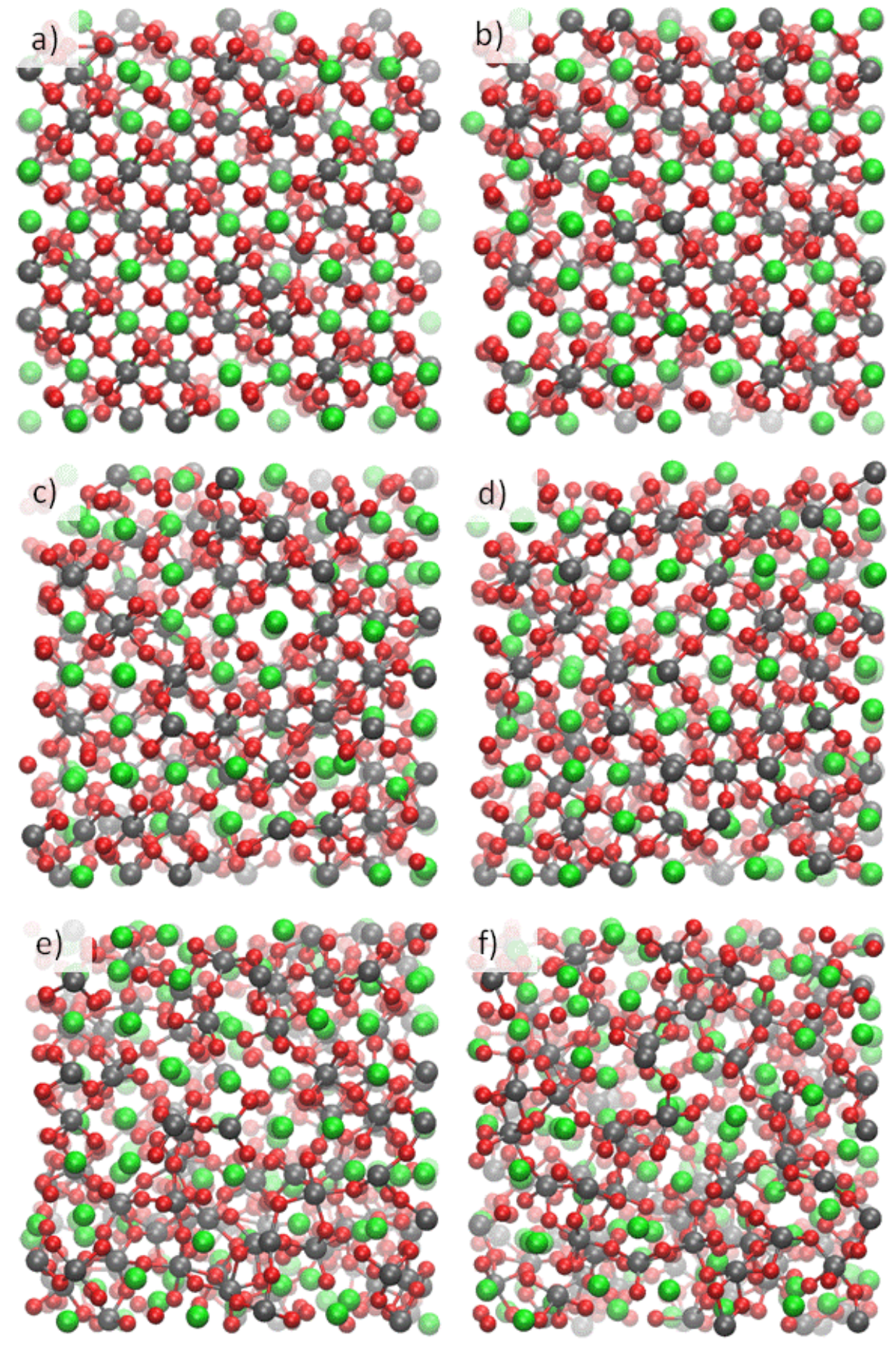

Fig. 7. Projection of atom positions in $\mathrm{Gd}_{2} \mathrm{Ti}_{2} \mathrm{O}_{7}$ following a) 0.03 ; b) 0.125 ; c) 0.25 ; d) 0.375 ; e)

0.5 and f) 0.625 displacements per cation. $\mathrm{Gd}, \mathrm{Ti}$ and $\mathrm{O}$ are represented by green, grey and red spheres, respectively. 

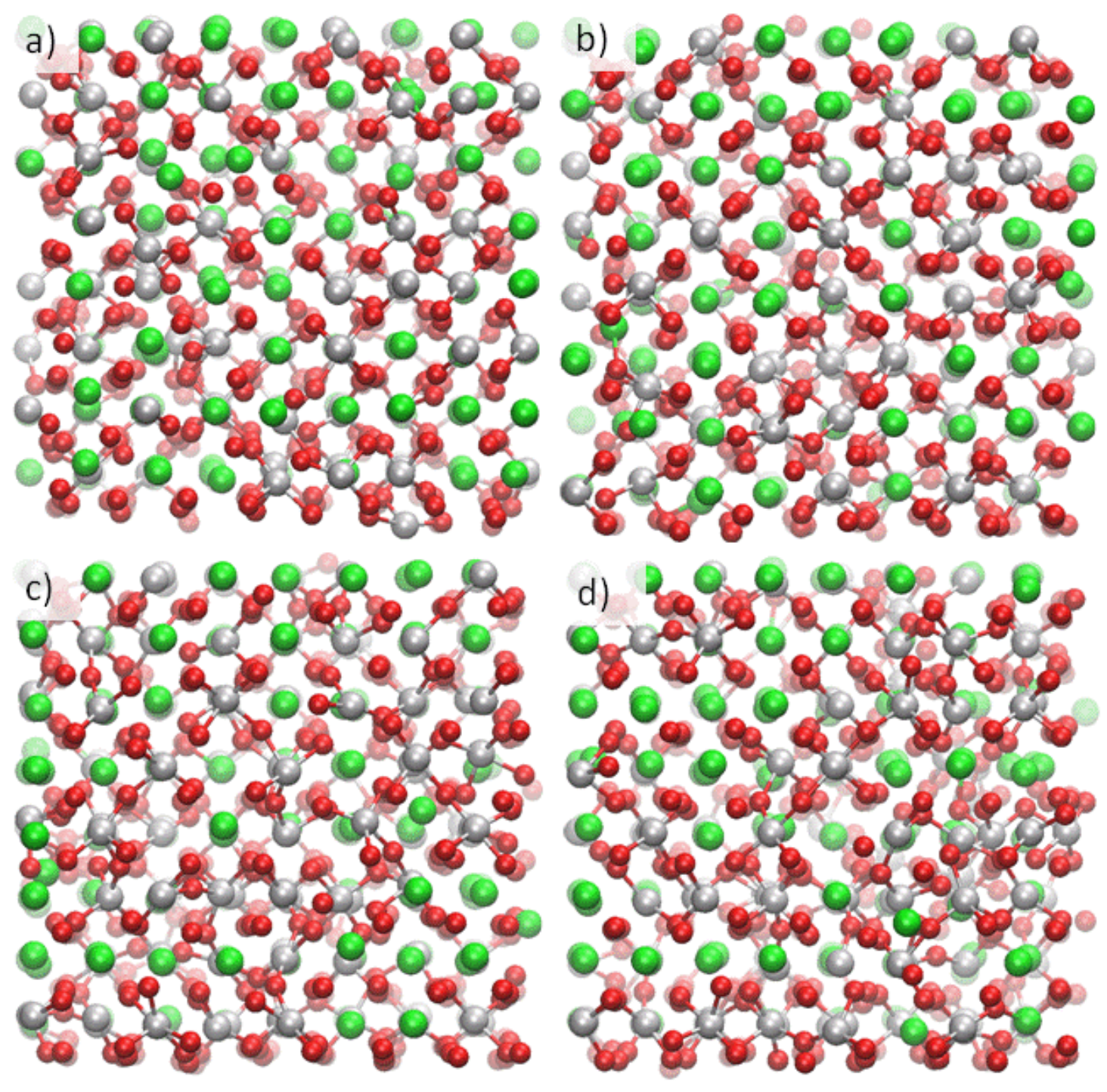

Fig. 8. Projection of atom positions in $\mathrm{Gd}_{2} \mathrm{Zr}_{2} \mathrm{O}_{7}$ following a) 0.25 ; b) 0.5 ; c) 0.75 and d) 1.0 displacements per cation. $\mathrm{Gd}, \mathrm{Zr}$ and $\mathrm{O}$ are represented by green, grey and red spheres, respectively. 